\title{
Spatial-temporal Patterns of Snow Cover in Western Canada
}

\author{
C. J. Farmer ${ }^{1}$, T. A. Nelson ${ }^{1 *}$, M.A. Wulder², and C. Derksen ${ }^{3}$
}

\section{Affiliations:}

${ }^{1}$ Spatial Pattern Analysis and Research (SPAR) Laboratory, University of Victoria, Department of Geography, Victoria, British Columbia, V8W 3R4, Canada

${ }^{2}$ Canadian Forest Service, Pacific Forestry Centre, Natural Resources Canada, Victoria, British Columbia, V8Z 1M5, Canada

${ }^{3}$ Environment Canada, Atmospheric Science and Technology Directorate, Climate Research Division, Climate Processes Section, Downsview, Ontario, M3H 5T4, Canada

\section{${ }^{*}$ Corresponding Author:}

T.A. Nelson

University of Victoria, Department of Geography, PO Box 3060, Victoria British Columbia, V8W 3R4, Canada.

Email: trisalyn@uvic.ca.

\section{Pre-print of published version.}

\section{Reference:}

Farmer, C.J.Q., Nelson, T.A., Wulder, M.A., and Derksen, C. (2009) Spatial-temporal patterns of snow cover in western Canada. The Canadian Geographer 53(4): 473-487.

\section{DOI:}

10.1111/j.1541-0064.2009.00283.x

\section{Disclaimer:}

The PDF document is a copy of the final version of this manuscript that was subsequently accepted by the journal for publication. The paper has been through peer review, but it has not been subject to any additional copy-editing or journal specific formatting (so will look different from the final version of record, which may be accessed following the DOI above depending on your access situation). 


\begin{abstract}
Snow cover is often measured as snow water equivalent (SWE), which refers to the amount of water stored in a snow-pack that would be available upon melting. Snow cover and SWE represent the source of local snow melt release, and are sensitive to regional and global atmospheric circulation, and changes in climate. Monitoring SWE using satellite-based passive microwave radiometry has provided nearly three decades of continuous data for North America.

The availability of spatially and temporally extensive SWE data enables a better understanding of the nature of space-time trends in snow cover, changes in these trends, and linking these trends to underlying landscape and terrain characteristics. To address these interests, we quantify the spatial pattern of SWE by applying a local measure of spatial autocorrelation to twenty five years of mean February SWE derived from passive microwave retrievals. Using a method for characterizing the temporal trends in the spatial pattern of SWE, temporal trends and variability in spatial autocorrelation are quantified. Results indicate that within the Canadian Prairies, extreme values of SWE are becoming more spatially coherent, with potential impacts on water availability, and hazards such as flooding. These results also highlight the need for Canadian ecological management units that consider winter conditions.
\end{abstract}

\title{
Résumé
}

Une couche de neige est fréquenment mesurée en équivalence d'eau de la neige (SWE) pour référer a la quantité d'eau provenant de la fonte d'un banc de neige empaquetée. SWE est important pour mesurer les conditions atmosphériques régionales et globals, le climate, et les cycles hydologiques. La surveillance du SWE en utilisant satellites a la base de micro-ondes rediométriques a forni des données continues au cours de deux décennies en Amérique du Nord.

Le fait de posséder des données provenant de l'espace et celles du SWE nous fournit la possibilité d'une meilleure compréhension des tendances actuelles et futures de chutes de neige reliées aux caractéristiques de différents terrains. On quantifie les tendances du SWE avec statistiques de l'espace spatial en appliquant des mesures locales d'autocorrélation aux données recouvertes en Février au cours de 25 ans. Utilisant une méthode innovatrice pour caractériser les tendances temporel des modèles spatiales en SWE, on quantifie les tendances et variabilité dans l'autocorrélation du SWE. Toutes les données indiquent qu'à l'intérieur des Prairies Canadiennes, en cas de SWE excessifs, certaines régions a pu devenir plus susceptibles d'inondation. De plus, les résultats signalent le besoin qu'à la gérance Canadienne des unités écologiques de porter attention aux conditions hivernales.

\section{Introduction}

The spatial and temporal distributions of terrestrial snow cover impacts local snowmelt release (Luce et al. 1998), global and regional atmospheric circulation (Barnett et al. 1989; Derksen et al. 1998a), as well as global and local climate and hydrological cycles (Derksen and McKay 2006; Derksen et al. 2000; Wulder et al. 2007; Serreze et al. 2000). The sensitivity of terrestrial snow cover to atmospheric conditions and overlying air temperatures also makes it a useful indicator of climate change (Derksen et al. 2000; Goodison and Walker 1993). As such, examining the spatial distribution of terrestrial snow cover over time aids in understanding current and future trends in climate (Wulder et al. 2007).

Snow cover is often measured as snow water equivalent (SWE), which refers to the amount of water (commonly expressed as a depth in millimetres) stored in a snow-pack that would be 
available upon melting (NSIDC 2007). Due to issues with in situ data collection, traditional methods for snow cover and depth measurement are spatially and temporally sparse (Walker and Goodison 2000; Wulder et al. 2007). However, as climate and hydrological models have become more accurate, high quality SWE datasets over large areas throughout Canada (Derksen et al. 2000; Derksen and McKay 2006; Walker and Goodison 2000) and the northern hemisphere (Tait 1996; Pulliainen and Halliskainen 2001) have been developed using passive microwave radiometry.

In Canada, much of the total annual precipitation falls in the form of snow, so snowmelt represents a significant portion of the total water available for streamflow, agricultural use, reservoir management, and natural processes (Brown et al. 2000; Derksen and McKay 2006; Tait 1996). To address data requirements in various communities, the Climate Research Division of Environment Canada established a program to develop algorithms for estimating SWE in open environments, as well as coniferous, deciduous, and sparse classes of forest cover (Walker and Goodison 2000; Goïta et al. 2003).

These algorithms have been used to generate weekly SWE maps for diverse application areas including water resource management, hydropower generation, and weather forecasting (Goodison et al. 1990; Pietroniro and Leconte 2005).

The Scanning Multichannel Microwave Radiometer (SMMR 1978-1987), and the Special Sensor Microwave/Imager (SSM/I, 1987-present) provide over two decades of continuous satellite data for North America from which SWE can be derived. Previous space-time SWE research emphasized spatial trends of snow cover and SWE over short time periods (e.g., Derksen et al. 1998a, 1998b), or coarse-scale spatial trends (i.e. regional analysis) of snow cover and SWE for longer time-series (e.g., Brown 2000; Laternser and Schneebeli 2003).

The characteristics of the satellite passive microwave record means a new perspective on the spatial-temporal trends in SWE can be investigated. For instance, it is possible to apply measures of spatial autocorrelation to quantify if and how SWE values deviate from a random geographical distribution (Boots 2002). In the present study, measures of spatial autocorrelation are used to identify clusters of extreme high and low SWE values and to investigate trends over multiple years. This type of analysis can be used to locate areas of SWE anomalies relative to average conditions within the study region. By characterizing temporal trends in SWE clusters over time, it is possible to examine persistence and/or variability of these spatial patterns, outlining areas where SWE may be more or less sensitive to climate variability. Furthermore, by comparing the spatial-temporal patterns in SWE with environmental data, such as land-cover, ecosystems, and elevation, hypotheses on the nature of SWE distribution and variability can be formulated.

The general goal of the present paper is to quantify how the spatial patterns of SWE vary across the study region, and how these spatial patterns vary through time. The specific objectives are:

- to quantify the level of spatial association and identify trends in locations of significant clusters of high or low SWE for each year in the time series,

- to characterize the relationship between existing ecological management units and spatial-temporal trends in SWE, and

- to quantify how spatial-temporal trends in SWE relate to elevation. 
A measure of spatial association is used to describe geographical variation in the dominant spatial patterns of SWE. Prevailing temporal trends in SWE spatial association are then quantified using a novel method for quantifying temporal trend over multiple time periods. Locations with space-time trends that indicate the potential for sensitivity to climate variability are highlighted and the underlying landscape and terrain characteristics are related to trends in the space-time patterns of SWE.

\section{Study Area and Data}

\section{$\underline{\text { Study area }}$}

The study region is constrained to the interior regions of the Canadian prairies, and is comprised of both the Prairies and Boreal Plains ecozones (Figure 1). These ecozones were selected due to strong interannual variability in SWE in large portions of these zones (Wulder et al. 2007). The Prairie and Boreal Plains ecozones are characterized by relatively flat, rolling plains and lowlying valleys. Vegetation is primarily restricted to shrubs and sparse treed areas, with cold winters and short warm summers. In the Prairie ecozone, approximately 25 percent of the total precipitation falls as snow (Wiken et al. 1996), and the timing of this is generally constrained to the winter months and impacts ecological processes in the spring during runoff. Furthermore, according to Wulder et al. (2007), regions which may be classified as either open prairie or open tundra appear to contain the most temporally variable SWE estimates. As such, these areas are particularly susceptible to the impacts of climate change.

Brightness temperature data

The primary data source used for the present analysis is brightness or absolute temperatures (in Kelvin) acquired by both the SSM/I passive microwave radiometer on board the Defense Meteorological Satellite Program (DMSP) F13 satellite and the SMMR passive microwave radiometer on board the NIMBUS-7 satellite. The estimation of SWE from dry snow is primarily a function of changes in the scattering of naturally emitted microwave radiation caused by snow crystals, such that as the depth and density of the snow increases, the amount of volume scattering also increases (Foster et al. 1999). Given this relationship, detected microwave brightness temperature decreases with increasing snow depth due to the greater amount of snow crystals available for volume scattering of the microwave signal (Derksen et al. 2000). Shorter wavelength energy $(37 \mathrm{GHz} / 8108 \mu \mathrm{m})$ is more readily scattered by crystals in the snow pack than longer wavelength energy $(19 \mathrm{GHz} / 15789 \mu \mathrm{m})$. Thus, to quantify SWE, the difference between the shorter wavelength microwave energy and the longer wavelength energy can be used. Although the estimation of SWE from passive microwave is theoretically simple, operational issues arise in practice. Potential complications may develop from a range of physical parameters including: snow wetness, snow crystal size, depth hoar, and ice crusts, as well as the underlying land cover, topography, and overlying vegetation (Derksen et al. 2000).

The SSM/I and SMMR data are provided in the Equal Area Scalable Earth Grid (EASE-Grid) format (see Armstrong and Brodzik 1995) with a spatial resolution of $25 \mathrm{~km}$. Data are obtained from the National Snow and Ice Data Center (Knowles et al. 1999; Armstrong et al. 1994-2002). The difference between the $37 \mathrm{GHz}$ and $19 \mathrm{GHz}$ vertically polarized channels were investigated in this study. These are the conventional frequencies used to estimate SWE in most algorithms (Goodison 1989). We decided to utilize brightness temperature difference (37-19 GHz) instead of SWE values retrieved using the Environment Canada open prairie algorithm (Goodison and Walker 1995) in order to remove one layer of data processing and directly apply the statistical 
techniques to the satellite measurements. The prairie SWE algorithm is a linear equation, so the brightness temperature difference is a direct proxy for SWE: a larger difference represents greater SWE. Using mean February brightness temperature differences allowed spatial and temporal variability in spatial association to be measured when snow extent and depth for this region of North America is expected to be near the maximum (McCabe and Legates 1995; Derksen et al. 2003).

\section{Ecoregions and ecoprovinces}

In order to provide a finer-scale spatial context in which to consider the impacts of terrestrial characteristics on the spatial-temporal pattern of SWE , the study area is further broken down into terrestrial ecoprovinces and ecoregions. Ecoprovinces are largely based on characterizing major assemblages of structural or surface forms and faunal realms, as well as vegetation, hydrology, soil, and macroclimates (Marshall et al. 1998). Ecoprovinces were created as part of an ecological framework to address the environmental concerns of the Commission for Environmental Cooperation (CEC) by Canada, Mexico and the United States (Marshall and Schut 1999). Subsequently, ecoregions subdivide the terrestrial ecoprovinces, and are characterized by distinctive large order landforms or assemblages of regional landforms, small order macro or mesoclimates, vegetation, soil, and water features (Wiken et al. 1996). These ecological units are useful for describing the major driving factors of an ecosystem, and as such are useful for conservation planning and analysis (Kerr and Deguise 2004). The six terrestrial ecoprovinces, and twenty nine ecoregions in the study area are presented in Table 1; in addition, Figure 1 shows the individual ecoregions.

\section{Elevation}

Spatial-temporal patterns in SWE are also interpreted using elevation, enabling an assessment of the relationship between SWE spatial-temporal features and ground surface characteristics. Elevation data are obtained from a digital elevation model (DEM) with a $1 \mathrm{~km}$ spatial resolution. The DEM (GTOPO30) is a global digital elevation model produced as part of a collaborative effort led by the US Geological Survey's (USGS) EROS Data Center (Gesch et al. 1999). It is reported to be accurate to within \pm 30 vertical metres in most areas (Defense Mapping Agency 1986; US Geological Survey 1993). The DEM will be used to determine elevation, which may have some bearing on the amount and type of snow deposition.

\section{Methods}

\section{Quantifying spatial patterns}

Quantifying the spatial interaction of localized areas within a study region provides information on the location, type, and magnitude of local SWE extremes. Aspatial analysis generalizes spatial trends, but by implicitly considering the spatial distribution of SWE within a study region, new patterns and variability emerge, and can be quantified. The Getis and Ord $G_{i}{ }^{*}$ statistic (Getis and Ord 1992; Ord and Getis 1995), is a local measure of spatial association designed to highlight spatial clusters of similarly high or low values that are extreme relative to average trends in the data (Boots 2002). The $G_{i}{ }^{*}$ statistic assigns a measure of the level of spatial association at each individual pixel, highlighting areas which display strong brightness temperature gradients (both high and low). 
In general, the $G_{i}{ }^{*}$ statistic is designed to compare spatially local averages to global averages by considering both the locational, and attribute relationship between each pixel (i) and its surrounding neighbours $(j)$ (Boots 2002). Formally, the $G_{i}{ }^{*}$ statistic is given as

$$
G_{i}=\sum_{j} w_{i j} y_{i j} / \sum_{j} y_{i j} \text {, }
$$

where $w_{i j}$ defines the locational (spatial) relationship between $i$ and $j$, and is given a value of one if $i$ and $j$ are neighbours, and zero otherwise, whereas $y_{i j}$ defines the attribute (aspatial) relationship between $i$ and $j$., In this sense, the $G_{i}{ }^{*}$ statistic is the sum of pixel values within a neighbourhood centered on $i$, relative to the sum of all pixel values within the study region (Boots 2002). Ord and Getis (1995) derive a standardized version of the $G_{i}{ }^{*}$ statistic and values are reported in a z-score standardized form. Using z-scores, analysis using $G_{i}{ }^{*}$ is suitable for comparison between different time periods and datasets. For details on this standardized form, see Ord and Getis (1995). All reported $G_{i}{ }^{*}$ results in the current paper are given in the standardized form.

In order to maintain the finest spatial grain of analysis possible while maintaining stability of the $G_{i}{ }^{*}$ statistic, the locational relationship in this analysis is based on all pixels within a $3 \times 3$ grid (75 km x $75 \mathrm{~km}$ ) surrounding the target location $i$. This ensures statistical neighbourhoods have a minimum of 9 pixels (inclusive), which is the above the suggested minimum number of neighbours required to maintain validity of the statistic (Boots 2002; Griffin et al. 1996). Due to issues of spatial dependence and multiple testing, which are problematic for many local spatial statistics, it is often best to consider $G_{i}{ }^{*}$ results as exploratory rather than confirmatory (Boots 2002; Sokal et al. 1998a, 1998b).

When interpreting the standardized $G_{i}{ }^{*}$ z-score values, a high value of $G_{i}{ }^{*}$ (strong positive) indicates clustering of extreme high values, and a low value of $G_{i}^{*}$ (strong negative) indicates clustering of extreme low values. Mid range values of $G_{i}{ }^{*}$ can be caused by both clustering of values that are near the average global value, as well as an absence of clustering (Tiefelsdorf and Boots 1997). Therefore, the $G_{i}{ }^{*}$ statistic is useful for capturing spatial clusters of values that are extreme relative to the mean.

In the current analysis, $G_{i}{ }^{*}$ z-score values are categorized into three classes: greater than or equal to 2 standard deviations from the mean indicates a cluster of high values, less than or equal to -2 standard deviations from the mean indicates a cluster of low values, and greater than -2 and less than 2 standard deviations from the mean indicates no significant clustering in extreme values. This classification allows the statistics highlights areas of significant clustering with respect to the mean, and is the standard approach to interpreting $G_{i}{ }^{*}$.

\section{Interannual spatial association}

Computing the $G_{i}{ }^{*}$ statistic for each successive year $\left(y_{i}-y_{n}\right)$ in the study period provides a means for interannual comparison of the spatial pattern in extreme SWE values. To aid interpretation, a cluster of SWEs is defined as a grouping of spatially adjacent significant values (both high and low). Scatterplots which examine the relationship between the number of significant pixels in the study region (significant spatial autocorrelation in both high and low SWE), and the number of significant clusters ( both high and low SWE) were generated to compare how clusters of extreme SWE change relative to the overall abundance or absence of extreme values. Exploratory analysis through iteratively plotting different time periods, indicated that relationships between the number of clusters and pixels differed in two primary time 
periods: 1979-1988 and 1989-2002, and by generating scatterplots for each time period we highlight how the spatial processes of SWE change through time. To compare differences in the slope of the observed relationships (number of clusters vs. pixel, comparisons between different temporal windows were performed using standard t-tests.

\section{Temporal variability and trends}

Changes in the level of spatial association through time were quantified to assess interannual trends in $G_{i}^{*}$ results. A spatial grid of individual time series' was generated, each with its own temporal signature. These time series were then individually analyzed for temporal trends and variability using methods which treat each pixel within the study region as a separate temporal vector.

Several measures were used to quantify temporal trends in the SWE data. The observed SWE time series' were compared to hypothetical random SWE time series to assess the hypothesis that the temporal SWE observations are independent and identically distributed along the time series, and thus equally likely to have occurred in any order (Kendall and Ord 1990). To assess hypotheses of randomness in the time series, turning points were used. Turning points may be defined as either a peak or trough within a time series, and usually refers to a value which is either greater than (peak) or less than (trough) its neighbouring values (Kendall and Ord 1990). The test statistic $(p)$ is a count of the number of peaks and troughs in the time series, and according to Kendall and Ord (1990), as the total number of time periods ( $n$ ) increases, the distribution of the test statistic approaches normality, with an expected value of $(2 n-4) / 3$, and variance equal to $(16 n-29) / 90$. Thus, the statistic may be represented as a standard variate, such that the expected number of peaks $E(p)$ is subtracted from the observed value, and divided by the square root of the variance in $p$ :

$$
z(p)=\frac{p-E(p)}{[\operatorname{var}(p)]^{1 / 2}} .
$$

Two descriptive measures provide further insight into the temporal patterns of SWE observed in the study area: relative variability, and the modal state of each individual the temporal vector. The relative variability of SWE spatial association, which is simply the count of the number of state changes (the number of times a value increases or decreases from a previous value in the time series), and the modal state of the time series.

\section{Comparison with ecoregions and elevation}

Comparing the frequency distribution of temporal metrics, between ecoregions, and the frequency distribution of elevations for different temporal metrics, enables characterization of spatial and temporal features. Ecoregions were intersected with variability in SWE spatial autocorrelation for each pixel in the study region. A quantitative comparison of the distribution of pixels with statistically significant variability (both high and low) in $G_{i}{ }^{*}$ z-scores over each ecoregion was performed using a Mann-Whitney U test (Hollander and Wolfe 1999; Mann and Whitney 1947). This highlights ecoregions with significantly different distributions of variability in computed $G_{i}{ }^{*}$ z-scores. In addition, relationships between the temporal trends in SWE spatial autocorrelation and elevation were quantified using the Mann-Whitney $U$ test to compare variations in elevation for both variability and modal state classes. A similar comparison was performed for variability classes, to compare elevation frequency distributions. 


\section{Results}

Interannual spatial association

The spatial distribution of clustering in extreme SWE values is variable over the study region and through time. The relationship between individual significant pixels and significant clusters gives an indication of the pattern of spatial association within the study region in any given year. Initial analysis revealed a break in the observed relationship between 1988 and 1989. Figure 2a shows the relationship between the number of individual significant pixels (spatial autocorrelation in both high and low SWE), and the number of significant clusters of SWE values (spatial autocorrelation in both high and low SWE) from 1979-1988. As the number of individual significant pixels increases, the number of contiguous clusters also increases, indicating that pixels with positive spatial autocorrelation in extreme high SWE values are occurring as smaller isolated pockets, rather than contributing to existing clusters. The observed relationship for significant spatial autocorrelation of pixels and clusters of high SWE (black line) is significant at a 95 percent confidence level $(\mathrm{t}=7.016$, $\mathrm{p}$-value $=0.000)$; whereas, significant spatial autocorrelation in low SWE (grey line) is not significant $(\mathrm{t}=0.314$, $\mathrm{p}$-value $=0.762$ ).

Figure 2b presents the number of individual significant pixels (spatial autocorrelation in both high and low SWE) with respect to the number of significant clusters (spatial autocorrelation in both high and low SWE) for the years 1989-2004. The relationship between the number of individual significant pixels and the number of individual clusters is inversely related in both cases, such that, in general, as the number of significant pixels (and total area that the clusters occupy) increases, the number of clusters decreases. This indicates that the scale of spatial association in extreme SWE is increasing through time, and that significant pixels are contributing to larger, spatially coherent clusters. As a result, the difference in the slope of the relationship between the two time periods ( $\mathrm{a}$ and $\mathrm{b}$ ) for significant spatial autocorrelation in high SWE is significant $(t=22.609$, $\mathrm{p}$-value $=0.000)$. This is further evidence that prior to 1989 , SWE spatial structure was different, with extreme events less spatially coherent than during the 1989-2004 time period.

\section{Relationships with ecoregions and elevation}

Characterization of the relationship between existing ecological management units and the spatial-temporal trends in SWE, was given by an initial evaluation of relative variability for each ecoregion using the Mann-Whitney $U$ test. When comparing the distribution of relative variability values within each ecoregion with the distribution of relative variability values of all other ecoregions, in most cases no significant differences were observed (p-values $>0.05$ ). Only a single ecoregion in the periphery of the north western portion of the study region was found to display a significantly different distribution of relative variability values (z-value $=-6.71$, pvalue $=0.000$ ). The Clear Hills Upland, located in the Boreal Plains ecozone displayed a range in relative variability values which was significantly smaller than the rest of the study region, and showed no significant variability along the time series. Figure 3 shows the distribution of variability values throughout the study region. The distribution of variability values throughout the study region shows strong spatial dependence, with similar levels of variability occurring together across the landscape (Moran's I = 0.559 p-value $=0.010$ ). For information on the Moran statistic, see (Cliff and Ord 1981). However, the distribution and boundaries of the ecoregions do not coincide with the distribution of variability values (see Figure 1 for ecoregion boundaries). 
The distribution of elevations for modal state classes showing significant spatial autocorrelation in both high and low SWE values were found to be significantly different from each other, as well as from the study area as a whole (p-values $<=0.05$ ). Figure 4 shows the distribution and summary statistics of elevations for significant spatial autocorrelation in high SWE values (Figure 4a), and low SWE values (Figure $4 \mathrm{~b}$ ) respectively. While the number of pixels in the study region displaying spatial autocorrelation in high SWE values $(n=423)$ is larger than the number of pixels displaying significant spatial autocorrelation in low SWE values $(n=231)$, the level of dispersion is lower for spatial autocorrelation in low SWE values $(\mathrm{CV}=0.22$ vs. $\mathrm{CV}=$ 0.48). This is partly influenced by the bimodal shape of the distribution of elevations in Figure 4b. Statistically significant spatial association in low SWE values occurs primarily over regions where elevations are \pm 1 standard deviation $(>860 \mathrm{~m}$ or $<341 \mathrm{~m})$ from the mean elevation (601 $\mathrm{m}$ ); therefore, spatial autocorrelation of low SWE values is restricted to the more 'extreme' elevations in the study region, particularly in the lowland regions, where over 40 percent of the data in this class are found.

Classifying variability into two statistical classes: significantly high variability in the spatial association of SWE through time (high variability), and significantly low variability in the spatial association of SWE through time (low variability), allows differences in the distributions of elevations between these two classes to be assessed. The Mann-Whitney U test indicates that the distribution of elevations for the low variability class is significantly different from the high variability class $(\mathrm{z}$-value $=-4.13, \mathrm{p}$-value $=0.00)$. Figure 5 characterizes how elevation is different between the high and low variability classes. Although the distributions of elevations for both classes are negatively skewed, the range in elevations is significantly different between the two classes (max. (high variability) $=1334 \mathrm{~m}$ vs. max. (low variability) $=2438 \mathrm{~m}$ ). As well, the elevations in Figure 5b fall into two clear groupings, with the majority of values occurring close to the mean (645 $\mathrm{m}$ ), and the rest of the values, in regions with significantly high elevations ( \pm 2 standard deviations from the mean). The differences in the range and distribution of elevations between these two classes are likely due to the spatial distribution of the variability values: all pixels which are characterized by significantly high variability in SWE spatial association are located in the northwestern and southeastern portions of the study region, with no pixels having high variability in SWE values through the central portion of the study region. This is contrasted by pixels which are classified as having significantly low temporal variability in SWE values, which are located randomly throughout the study region, and occur only in relatively small, isolated clusters of approximately $200 \mathrm{~km}^{2}$ on average.

\section{Discussion}

Significant spatial association occurred within the study region in most years, and the level of spatial association in SWE varies through both space and time. While the number of individual pixels showing significant spatial autocorrelation in both high and low SWE was increasing throughout the study period, they tended to coalesce into larger, contiguous regions of extreme (both high and low) SWE. These larger regions appear to coalesce towards the center of the study area, and are potentially important indicators of snow cover response to atmospheric circulation (e.g., Dewey 1977; Namias 1985; Liu and Yanai 2002; Gong et al. 2004),

The relationship between the number of individual significant pixels and contiguous clusters showing spatial autocorrelation in high SWE displayed significant variation through time. Extreme high SWE tended to become more spatially constrained after 1989, and large clusters occurred through the middle of the study region, in the northern portion of the Prairies ecozone, 
and Southern portion of the Boreal Plains ecozone. While this temporal transition appears to correspond closely with the SMMR and SSM/I transition eras, we are confident that the effects of this transition are mitigated first by the temporal averaging employed in the analysis (mean February values), and secondly through regridding the data to the $25 \mathrm{~km}$ EASE-Grid, such that the regridding absorbs any difference in the sampling characteristics of the sensors. Indeed, the clustering shift corresponds with a transition in regional southern prairie SWE anomalies observed both from passive microwave retrievals and conventional measurements (Figure 6). A period of predominantly negative anomalies shifted to predominantly positive anomalies during the late 1980's in both data records. The SWE anomalies were calculated from the satellite passive microwave data record using the prairie-specific retrieval algorithm of Goodison and Walker (1995) applied to brightness temperatures (1980-2006) corrected for homogeneity using the approach of Derksen and Walker (2003). The conventional observations represent regional averages of maximum snow depth from all available in situ observations (see Brown and Braaten 1998).

After 1989, the clustered region primarily comprises the Moist Mixed Grasslands, Aspen Parklands and Boreal Transition ecoregions of the Central Grassland and Parkland Prairies ecoprovinces, and to a lesser extent, the Slave River Lowland ecoregion in the northern reaches of the Boreal Plains Ecozone. In general, this group of ecoregions extends in a broad arc from southwestern Manitoba, north westward through Saskatchewan to its northern apex in central Alberta. As the climate continues to become more variable, the potential for flooding may be significantly altered in regions supplied by these areas (Olsen et al. 1999; Barnett et al. 2005). This relationship was not observed in the spatial autocorrelation of low SWE values, where the relationship between individual significant pixels and significant clusters remains non significant over both time periods (1979-1988 and 1989-2004), suggesting that the level and extent of clustering in dry winter conditions does not appear to be confined to any specific region.

While in some instances the Canadian terrestrial ecoregions may help to characterize some of the variability and trends in the spatial association of SWE, to a large degree these ecological units do not provide sufficient explanation for the observed spatial-temporal patterns in SWE. Differences in the variability of SWE spatial autocorrelation across the study region were observed, and displayed a significant spatial component. These differences were generally not related to ecoregions, which highlights the need for ecological management units which take into account SWE and other dominant winter processes. Ecoregions, and many other ecological management units, are generally based on spring and summer conditions, and as a result do not properly represent snow and winter conditions. In many regions of Canada, a large portion of the year is spent with snow, and any models or management strategies that include winter processes would benefit from a new classification systems which partitions the landscape with consideration to SWE, and other winter conditions.

Several trends emerged in the relationships between space-time trends in SWE and elevation. Firstly, regions of high and low temporal variability in SWE spatial patterns display significantly different distributions of elevation, suggesting that processes relating to SWE variability may be linked with elevation and/or some associated phenomenon, for example temperature or net radiation. Classifying pixels by modal state provides further evidence for a linkage between elevation and the spatial-temporal aspects of SWE spatial association. Regions of consistent spatial autocorrelation in high SWE were shown to be significantly different in terms of elevation from regions of consistent spatial autocorrelation in low SWE. A clear spatial 
separation of regions of consistently high modal state from regions of consistently low modal state was observed, and elevation was shown to be a strong determinant of this relationship. Low modal states occurred only in elevations extreme relative to the study region mean, and showed no overlap with regions of high consistent SWE spatial autocorrelation. In general, elevation has proven to be a relatively effective indicator of SWE spatial-temporal patterns across the study region, and while elevation has often been linked to SWE, the current analysis shows that as climate variability continues to increase over time. Elevation may also be a useful indicator of changing trends in SWE spatial and temporal patterns, with the greatest levels of variability anticipated to occur over elevation extremes (relative to the study region mean), such as upland and lowland regions.

\section{Conclusions}

Despite difficulties in characterizing SWE spatial-temporal features using current ecological management units, several dominant patterns in SWE spatial autocorrelation do emerge, and are captured by the various temporal metrics employed in the current analysis. Results revealed that the number of locations having significant spatial autocorrelation within the study region have increased both in number and size throughout the study period. These regions have continued to grow and coalesce into larger, contiguous regions of extreme SWE, particularly after 1989, where extreme high SWE has tended to become increasingly constrained to the grassland, parkland, and transition zones of the Central Grassland and Parkland Prairies ecoprovinces. These changes have potential impacts on runoff prediction, flood forecasting, and water resource management, which need to take into account the spatial nature of SWE. Furthermore, the relationships between the temporal characteristics of SWE and elevation have revealed that the level of SWE variability in a particular region may be significantly impacted by the distribution of elevations in that region, providing evidence for elevation-controlled SWE processes not captured by the ecoregions. The observed relationship between SWE variability and elevation, coupled with knowledge of the changing spatial configuration of SWE clusters through time indicates that regions of variable topography, such as those located in the northwestern portion of the Central Boreal Plains ecoprovince, may be differentially impacted by changing climate conditions.

Future research will use the detected spatial-temporal patterns of SWE to distinguish unique regimes of snow cover across Canada. SWE regimes describe the regular spatial and temporal patterns of SWE accumulation in individual regions, and are a major control of spatial and temporal patterns and processes in many ecosystems (Walker et al. 1999). Knowledge of the distribution of these SWE regimes will help analysts answer key questions regarding their impact on human and ecological processes. Further, based upon these findings, new ecological units could be developed that also integrate winter snow cover characteristics with the existing suite of determinants mainly based upon summer land cover conditions.

The methods demonstrated in this article may have benefit to other research which focuses on large area, spatial-temporal datasets collected over long time periods. By characterizing the temporal signature of spatial patterns over multiple time periods, it is possible to generate a mappable representation of the spatial-temporal data which is both intuitive and informative. Furthermore, by employing more complex temporal modeling and trend detection techniques as part of this overall methodology, analysts in fields such as water resource management, wildlife management, climate change research, and forestry may quantitatively characterize trends through time, and develop new knowledge to support management. 


\section{Acknowledgments}

The EASE-Grid brightness temperatures data were obtained from the EOSDIS National Snow and Ice Data Center Distributed Active Archive Center (NSIDC DAAC), University of Colorado at Boulder. This work was partially funded by the National Sciences and Engineering Research Council of Canada (NSERC). The authors would like to thank the three anonymous reviewers for their helpful comments on an earlier draft of this paper.

\section{References}

ARMSTRONG, R., and BRODZIK, M. 1995 'An earth-gridded SSM/I data set for cryospheric studies and global change monitoring’ Advanced Space Research 16, 10155-10163

ARMSTRONG, R., KNOWLES, K., BRODZIK, M., and HARDMAN, M. 1994 - 2002 'DMSP SSM/I Pathfinder Daily EASE-Grid Brightness Temperatures' (Boulder, CO: National Snow and Ice Data Center), CD-ROM

BARNETT, T. P., ADAM, J. C., and LETTENMAIER, D. P. 2005 'Potential impacts of a warming climate on water availability in snow-dominated regions’ Nature 438, 303-309

BARNETT, T. P., DUMENIL, L., SCHLESE, U., ROECKNER, E., and LATIF, M. 1989 'The effect of Eurasian snow cover on regional and global climate variations' Journal of the Atmospheric Sciences 46, 661-685

BOOTS, B. N. 2002 ‘Local measures of spatial association’ Écoscience 9, 168-176

BROWN, R. D. 2000 'Northern hemisphere snow cover variability and change, 1915-97' Journal of Climate 13, 2339-2355

BROWN, R. D., and R. O. BRAATEN. 1998. Spatial and temporal variability of Canadian monthly snow depths, 1946-1995. Atmosphere-Ocean. 36: 37-54

BROWN, R. D., A. WALKER, and B. GOODISON. 2000. Seasonal snow cover monitoring in Canada: An assessment of Canadian contributions for global climate monitoring. 57th Eastern Snow Conference, Syracuse, New York

CLIFF, A. D., and ORD, J. K. 1981 Spatial Processes: models and applications. (London: Pion)

DEFENCE MAPPING AGENCY, 1986. Defense Mapping Agency product specifications for digital terrain elevation data (DTED), 2nd ed. (Defense Mapping Agency Aerospace Center, St. Louis, Missouri)

DERKSEN, C., E. LEDREW, and B. GOODISON. 2000. Temporal and spatial variability of North American prairie snow cover (1988-1995) inferred from passive microwavederived snow water equivalent imagery. Water Resources Research 36: 255-266

DERKSEN, C. and M. MCKAY. 2006. The Canadian boreal snow water equivalent band. Atmosphere-Ocean 44: 305-320

DERKSEN, C., and A. WALKER. 2003. Identification of systematic bias in the cross-platform (SMMR and SSM/I) EASE-Grid brightness temperature time series. IEEE Transactions on Geoscience and Remote Sensing 4: 910-915

DERKSEN, C., A. WALKER, B. GOODISON. 2003. A comparison of 18 winter seasons of in situ and passive microwave derived snow water equivalent estimates in western Canada. Remote Sensing of Environment 88: 271-282 
DERKSEN, C., M. A. WULDER, E. LEDREW, and B. GOODISON. 1998a. Associations between spatially autocorrelated patterns of SSM/I derived Prairie snow cover and atmospheric circulation. Hydrological Processes 12: 2307-2316

1998b. Application of the Getis statistic to hemispheric and regional scale passive microwave derived snow water equivalent imagery. Geoscience and Remote Sensing Symposium Proceedings, IGARSS '98. 1998 IEEE International 2: 977-979

DEWEY, K. F. 1977. Daily maximum and minimum temperature forecasts and the influence of snow cover. Monthly Weather Review 105; 1594-1597

FOSTER, J. L., D. K. HALL, A. T. C. CHANG, A. RANGO, W. WERGIN, and E. ERBE. 1999. Effects of snow crystal shape on the scattering of passive microwave radiation. IEEE Transactions on Geoscience and Remote Sensing 37: 1165-1168

GESCH, D. B., K. L. VERDIN, and S. K. GREENLEE. 1999. New land surface digital elevation model covers the earth. EOS, Transactions of the American Geophysical Union 80: 6970.

GETIS, A., and J. K. ORD. 1992. The analysis of spatial association by use of distance statistics. Geographical Analysis 24: 189-206

GOÏTA, K., WALKER, A. E. AND GOODISON, B. E. 2003 'Algorithm development for the estimation of snow water equivalent in the boreal forest using passive microwave data' International Journal of Remote Sensing 24: 1097-1102

GONG, G., D. ENTEKHABI, J. COHEN, and D. ROBINSON. 2004. Sensitivity of atmospheric response to modeled snow anomaly characteristics. Journal of Geophysical Research 109: D06107

GOODISON, B. 1989. Determination of areal snow water equivalent on the Canadian prairies using passive microwave satellite data. Geoscience and Remote Sensing Symposium, 1989. IGARSS'89. 12th Canadian Symposium on Remote Sensing., 3: 1243-1246

GOODISON, B., and A. WALKER. 1993. Use of snow cover derived from satellite passive microwave data as an indicator of climate change. Annals of Glaciology 17: 137-142

1995. Canadian development and use of snow cover information from passive microwave satellite data' in Passive Microwave Remote Sensing of Land-Atmosphere Interactions, eds. B. CHOUDHURY, Y. KERR, E. NJOKU and P. PAMPALONI, (Utrecht: Netherlands), 245-262

GOODISON, B., A. WALKER, and F. THIRKETTLE. 1990. Determination of snow cover on the Canadian prairies using microwave data. Proceedings of the International Symposium on Remote Sensing and Water Resources, (Enschede: Netherlands), 127-136

GRIFFIN, P., A. GETIS, and E. GRIFFIN. 1996. Regional patterns of affirmative action compliance costs. The Annals of Regional Science 30: 321-340

HOLLANDER, M., and D. A. WOLFE. 1999. Nonparametric Statistical Methods, 2nd Edition. (New York: Wiley-Interscience)

KENDALL, M. G., and ORD, J. K. 1990, Time Series, 3rd Edition. (New York: Oxford University Press) 
KERR, J. T., and I. DEGUISE. 2004. Habitat loss and the limits to endangered species recovery. Ecology Letters 7: 1163-1169

KNOWLES, K., E. NJOKU, R. ARMSTRONG, and M. BRODZIK. 1999. Nimbus-7 SMMR Pathfinder daily EASE-Grid brightness temperatures. (Boulder, CO: National Snow and Ice Data Center), CD-ROM

LATERNSER, M., and M. SCHNEEBELI. 2003. Long-term snow climate trends of the Swiss Alps (1931-99). International Journal of Climatology 23: 733-750

LIU, X., and M. YANAI. 2002. Influence of Eurasian spring snow cover and Asian summer rainfall. International Journal of Climatology 22: 1075-1089

LUCE, C., D. TARBOTON, and K. COOLEY. 1998. The influence of the spatial distribution of snow on basin-average snowmelt. Hydrological Processes 12: 1671-1683

MANN, H. B., and D.R. WHITNEY. 1947. On a test of whether one of two random variables is stochastically larger than the other. Annals of Mathematical Statistics 18: 50-60

MARSHALL, I., and P. SCHUNT. 1999. A National Ecological Framework for Canada Overview. (Ottawa/Hull: Agriculture and Agri-Food Canada and Ecosystems Science Directorate, Environment Canada, State of Environment Directorate)

MARSHALL, I., E. WIKEN, and H. HIRVONEN. 1998. Terrestrial Ecoprovinces of Canada. (Ottawa/Hull: Ecosystem Sciences Directorate, Environment Canada and Research Branch, Agriculture and Agri-Food Canada) Draft Map at 1:7 500000 scale

MCCABE, G. J., and D. R. LEGATES. 1995. Relationships between 700 hPa height anomalies and April snow pack accumulations in the Western USA. International Journal of Climatology 15: 517-530

NAMIAS, J. 1985. Some empirical evidence for the influence of snow cover of temperature and precipitation. Monthly Weather Review 113: 1542-1553

NSIDC. 2007. National Snow and Ice Data Center.(Boulder, CO: National Snow and Ice Data Center) (Available at http://nsidc.org/, accessed September 2007)

OLSEN, J. R., J. R. STEDINGER, N. C. MATLAS, and E. Z. STAKHIY. 1999. Climate variability and flood frequency estimation for the upper Mississippi and lower Missouri rivers. Journal of the American Water Resources Association 35: 1509-1523

ORD, J. K., and A. GETIS. 1995. Local spatial autocorrelation statistics: Distributional issues and an application. Geographical Analysis 27: 286-306

PIETRONIRO, A., and R. LECONTE. 2005. A review of Canadian remote sensing and hydrology, 1999-2003. Hydrological Processes 19: 285-301

PULLIAINEN, J., and M. HALLISKAINEN. 2001. Retrieval of regional snow water equivalent from space-borne passive microwave observations. Remote Sensing of Environment 75:76-85

SERREZE, M., J. WALSH, F. CHAPIN, T. OSTERKAMP, M. DYURGEROV, V. ROMANOSKY, W. OECHEL, J. MORISON, T. ZHANG, and R. BARRY. 2000. 
Observational evidence of recent change in the northern high-latitude environment. Climatic Change 46:159-207

SOKAL, R. R. , N. L. ODEN, and B. A. THOMSON. 1998a. Local spatial autocorrelation in a biological model, Geographical Analysis 30: 331-353

1998b. Local spatial autocorrelation in biological variables. Biological Journal of the Linnean Society 65: 41-62

TAIT, A. 1996. Estimation of snow water equivalent using passive microwave radiation data. Geoscience and Remote Sensing Symposium, 2000. Proceedings. IGARSS 2000. IEEE 2000 International 4: 2005-2007

TIEFELSDORF, M., and B. BOOTS. 1997. A note on the extremities of local Moran's Ii and their impact on global Moran’s I. Geographical Analysis 29: 248-257

US GEOLOGICAL SURVEY. 1993. Digital Elevation Models, Data User Guide 5. (Reston, Virginia: US Geological Survey)

WALKER, A., and B. GOODISON. 2000. Challenges in determining snow water equivalent over Canada using microwave radiometry. Geoscience and Remote Sensing Symposium, 2000. Proceedings. IGARSS 2000. IEEE 2000 International 4: 1551-1554

WALKER, M. D., D. A. WALKER, J. M. WELKER, A. M. ARFT, T. BARDSLEY, P. D. BROOKS, J. T. FAHNESTOCK, M. H. JONES, M. LOSLEBEN, A. N. PARSONS, T. R. SEASTEDT, and P. L. TURNER. 1999. Long-term experimental manipulation of winter snow regime and summer temperature in arctic and alpine tundra. Hydrological Processes 13: 2315-2330

WIKEN, E., D. GAUTHIER, I. MARSHALL, K. LAWTON, and H. HIRVONEN. 1996. A Perspective on Canada's Ecosystems, (Ottawa, Ontario: Occasional Paper No. 14, Canadian Council on Ecological Areas)

WULDER, M. A., T. A. NELSON, C. DERKSEN, and D. SEEMANN. 2007. Snow cover variability across central Canada (1978-2002) derived from satellite passive microwave data. Climatic Change 82: 113-130

\section{Figure Captions}

Figure 1: Terrestrial ecoregion boundaries across the study region. Each number is the unique identifier for the corresponding ecoregion, these values are given in Table 1. Subset depicts the study region within the Boreal Plains and Prairies Terrestrial Ecozones of Canada.

Figure 2: Relationship between the number of individual pixels which show statistically significant spatial autocorrelation in both high (black) and low (grey) SWE, and the number of contiguous clusters of statistically significant pixels. Note: relationship from 1979-1988 (a) is significantly different than from 1989-2004 (b).

Figure 3: Spatial distribution of SWE temporal variability across the study region for 1979 to 2004. Lighter values correspond to significantly high temporal variability in SWE values, whereas darker values correspond to significantly low temporal variability in SWE values.

Figure 4: Distribution and summary of elevations for regions with statistically significant spatial autocorrelation in both high (a), and low (b) SWE. CV = Coefficient of variation. 
Figure 5: Distribution and summary of elevations for regions with significantly high variability (a), and significantly low variability (b). CV = Coefficient of variation.

Figure 6: Time series of southern Prairie SWE anomalies observed both from passive microwave retrievals (grey) and conventional measurements (black). Note shift from negative to positive anomalies during the late 1980s in both data records.

\section{Table Caption}

Table 1: List of Ecoregions and associated Ecozone and Ecoprovince. 


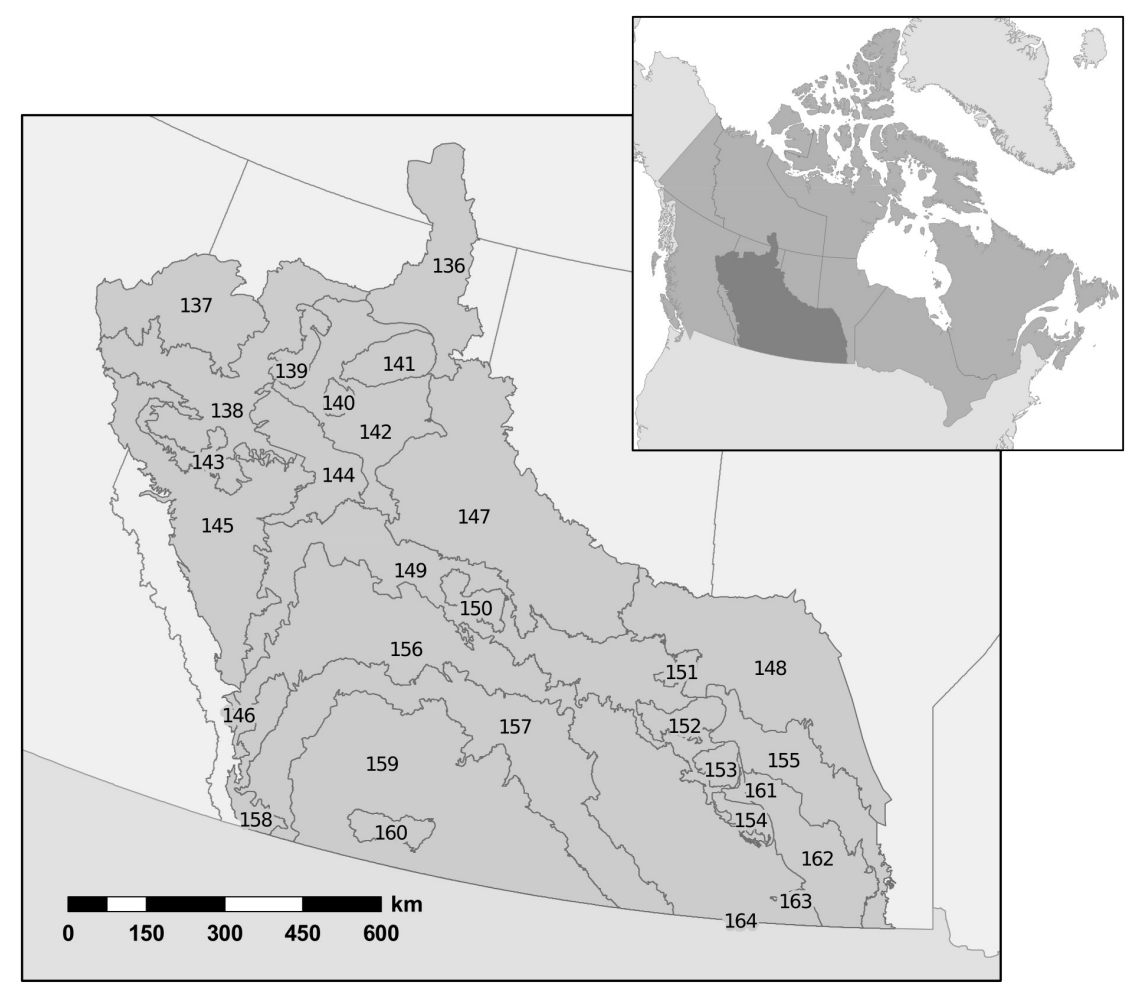

Figure 1: Terrestrial ecoregion boundaries across the study region. Each number is the unique identifier for the corresponding ecoregion, these values are given in Table 1. Subset depicts the study region within the Boreal Plains and Prairies Terrestrial Ecozones of Canada.

a)

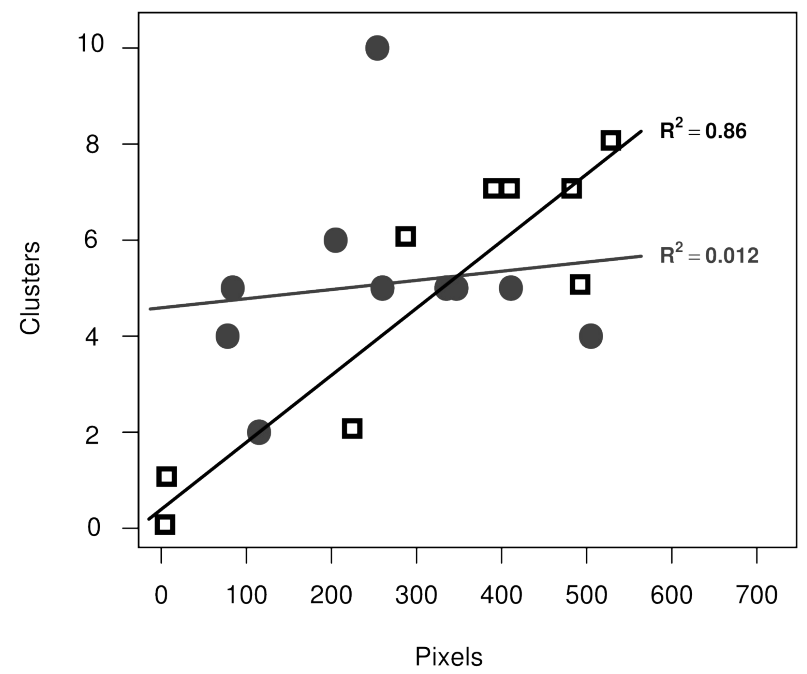

b)

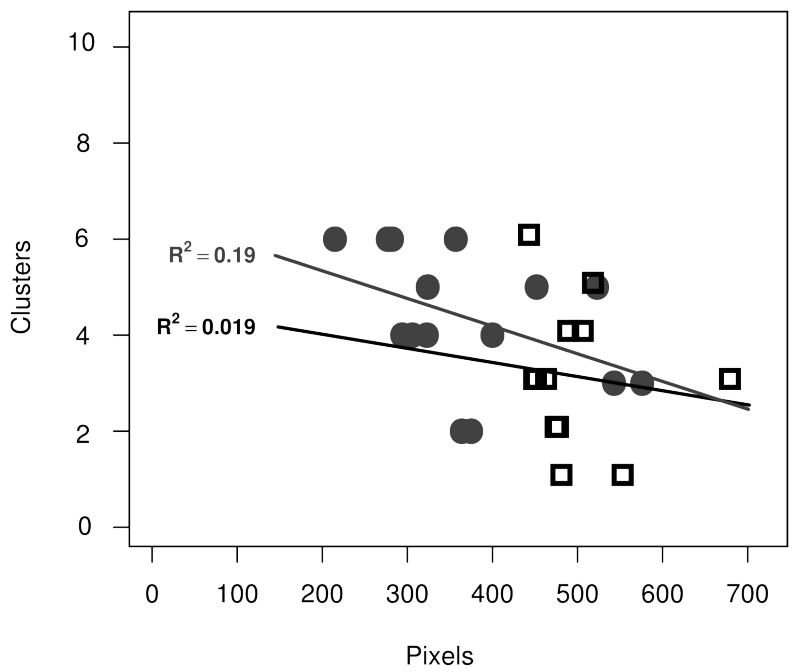

Figure 2: Relationship between the number of individual pixels which show statistically significant spatial autocorrelation in both high (black) and low (grey) SWE, and the number of contiguous clusters of statistically significant pixels. Note: relationship from 1979-1988 (a) is significantly different than from 1989-2004 (b). 


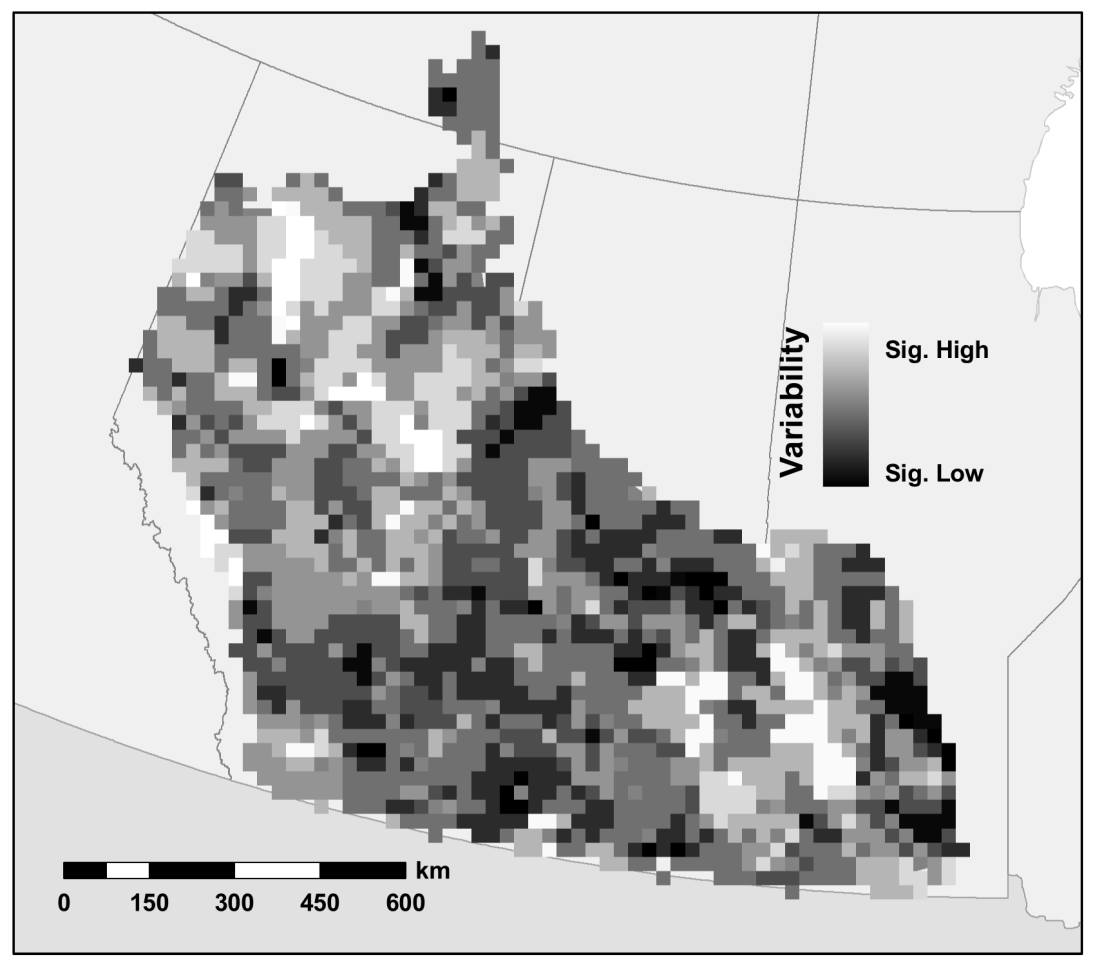

Figure 3: Spatial distribution of SWE temporal variability across the study region for 1979 to 2004. Lighter values correspond to significantly high temporal variability in SWE values, whereas darker values correspond to significantly low temporal variability in SWE values.

a)

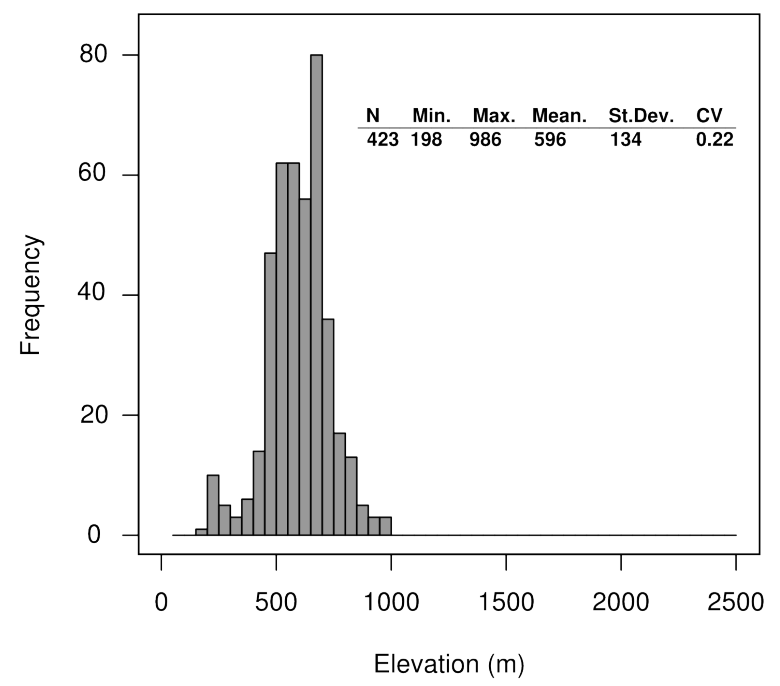

b)

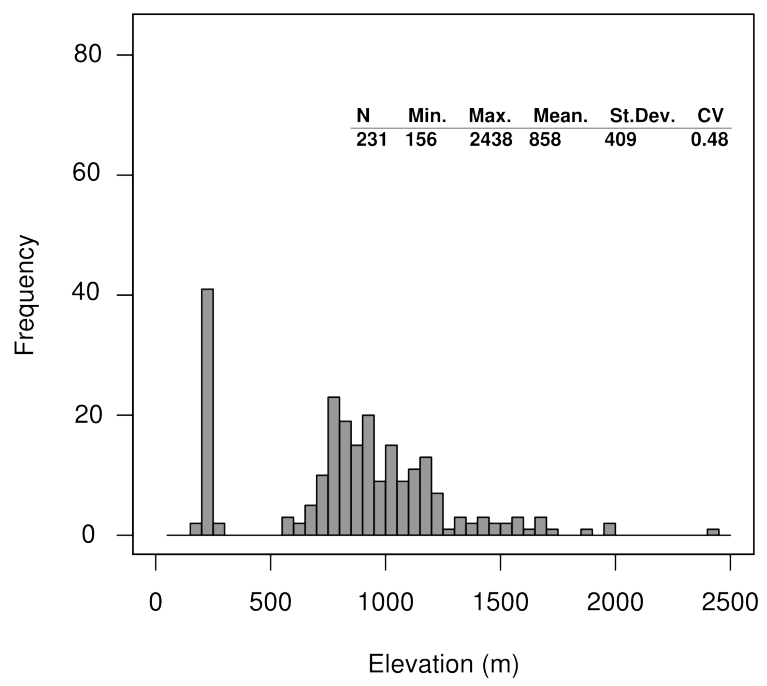

Figure 4: Distribution and summary of elevations for regions with statistically significant spatial autocorrelation in both high (a), and low (b) SWE. CV = Coefficient of variation. 
a)

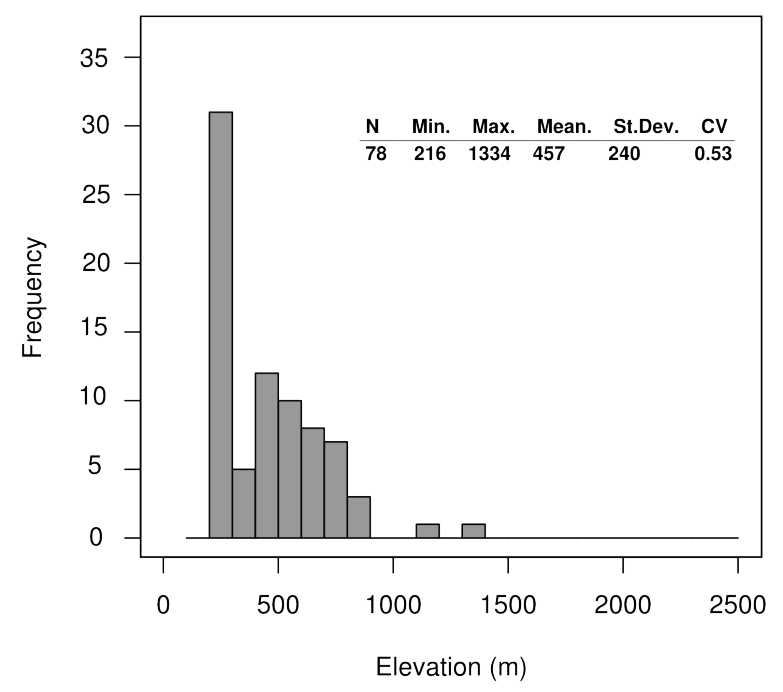

b)

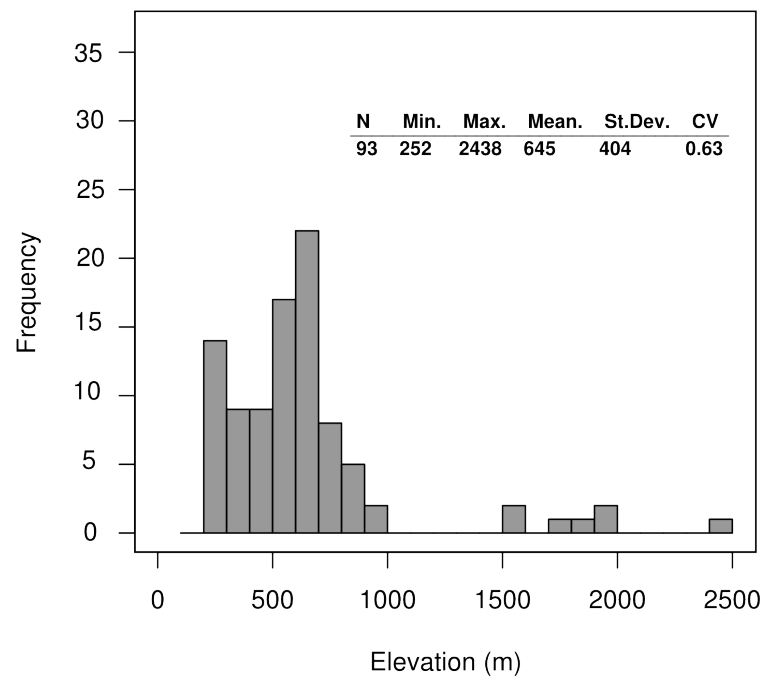

Figure 5: Distribution and summary of elevations for regions with significantly high variability (a), and significantly low variability (b). CV = Coefficient of variation.

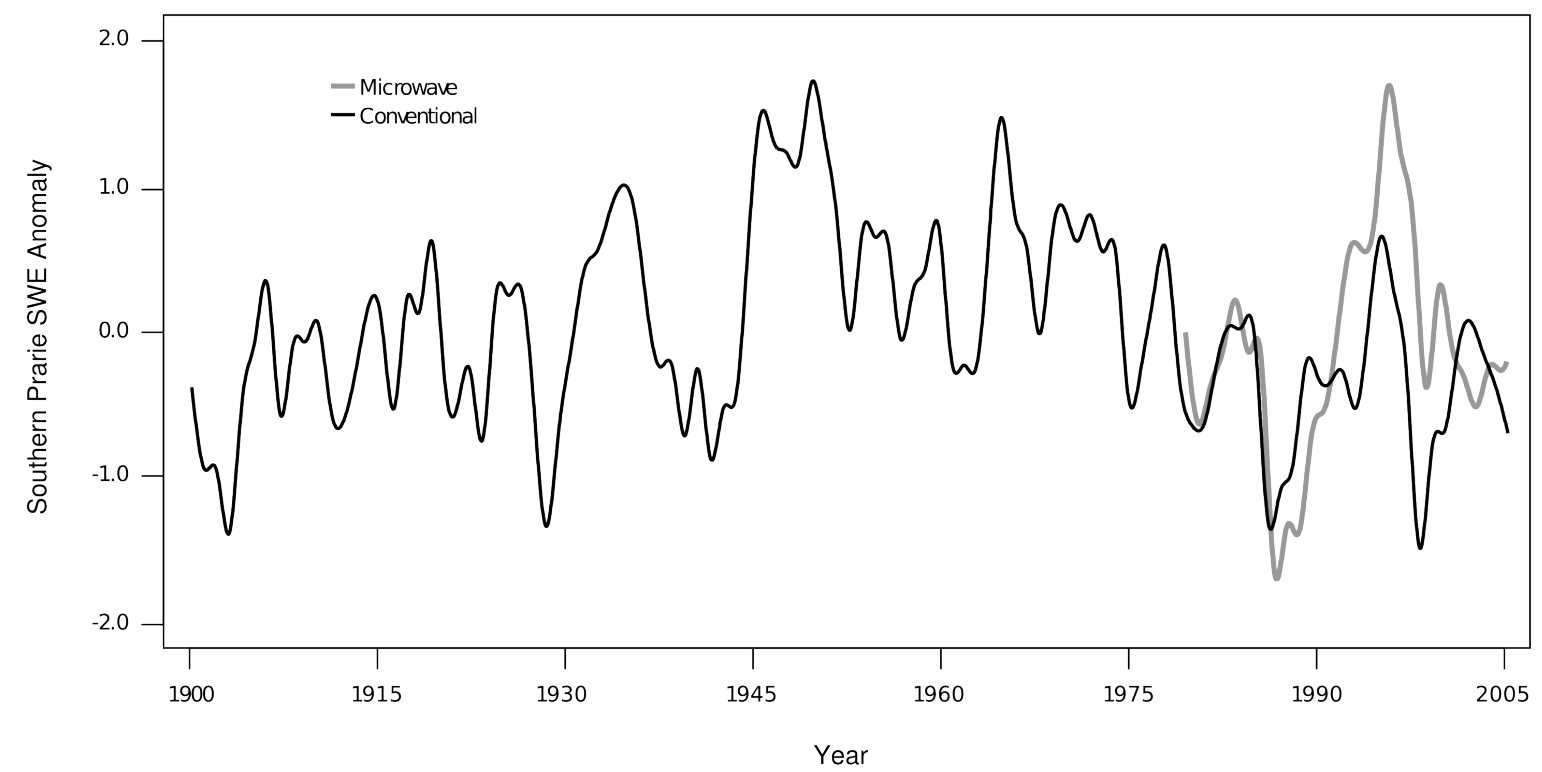

Figure 6: Time series of southern Prairie SWE anomalies observed both from passive microwave retrievals (grey) and conventional measurements (black). Note shift from negative to positive anomalies during the late 1980s in both data records. 
Table 1: List of Ecoregions and associated Ecozone and Ecoprovince.

\begin{tabular}{|c|c|c|c|}
\hline Ecozone & Ecoprovince & Ecoregion & Description \\
\hline \multirow[t]{13}{*}{ Boreal Plains } & Central Boreal Plains & Slave River Lowland (136) & Subhumid mid-boreal ecoclimate, with cool summers and long, cold winters. \\
\hline & Boreal Foothills & Clear Hills Upland (137) & Cool, short summers and cold winters with severe temperatures moderated by frequent chinooks. \\
\hline & Central Boreal Plains & Peace Lowland (138) & Subhumid, low boreal ecoclimate, marked by warmer summers than the surrounding areas. \\
\hline & Central Boreal Plains & Mid-Boreal Uplands (139-141) & Upland area, with subhimid mid-boreal ecoclimate, short, cool summers and cold winters. \\
\hline & Central Boreal Plains & Wabasca Lowland (142) & Lowland area, with subhumid mid-boreal ecoclimate, and cool summers and long, cold winters. \\
\hline & Central Boreal Plains & Western Boreal (143) & Poorly drained, low-relief plain, with cool, short summers and cold winters. \\
\hline & Central Boreal Plains & Mid-Boreal Uplands (144) & Upland area, with subhimid mid-boreal ecoclimate, short, cool summers and cold winters. \\
\hline & Boreal Foothills & Western Alberta Upland (145-146) & Upland area, marking transition between mid-boreal and mid-cordilleran vegatation. \\
\hline & Central Boreal Plains & Mid-Boreal Uplands (147) & Upland area, with subhimid mid-boreal ecoclimate, short, cool summers and cold winters. \\
\hline & Eastern Boreal Plains & Mid-Boreal Lowland (148) & Upland area, with subhimid mid-boreal ecoclimate, short, cool summers and cold winters. \\
\hline & Central Boreal Plains & Boreal Transition (149) & Transition zone, with subhumid low boreal ecolimate, and warm summers and cold winters. \\
\hline & Central Boreal Plains & Mid-Boreal Uplands (150-154) & Upland area, with subhimid mid-boreal ecoclimate, short, cool summers and cold winters. \\
\hline & Eastern Boreal Plains & Interlake Plain (155) & Subhumid low boreal ecoclimate, with warm summers and cold winters. \\
\hline \multirow[t]{8}{*}{ Prairies } & Parkland Prairies & Aspen Parkland (156) & Transitional grassland ecoclimate, with short, warm summers, and long, cold winters. \\
\hline & Central Grassland & Moist Mixed Grassland (157) & Northern extension of open grasslands in Interior Plains, with semiarid moisture conditions. \\
\hline & Central Grassland & Fescue Grassland (158) & Part of Rocky Mountain foothills, with warm summers and mild winters controlled by chinooks. \\
\hline & Central Grassland & Mixed Grassland (159) & Semiarid grasslands region, with summer moisture deficits, and low annual precipitation. \\
\hline & Central Grassland & Cypress Upland (160) & Upland region, with cooler, more moist climate than surrounding ecoregions. \\
\hline & Parkland Prairies & Aspen Parkland (161) & Transitional grassland ecoclimate, with cold winters with continuous snow cover. \\
\hline & Eastern Prairies & Lake Manitoba Plain (162) & Transitional zone, with warmest and most humid regions in the Canadian prairies \\
\hline & Parkland Prairies & Boreal Transition (163-164) & Elevated upland area, with high annual precipitation. \\
\hline
\end{tabular}

